\title{
Uma Revisão de Dermohipodermite Aguda Bacteriana: A Diabetes Mellitus Não Influencia a sua Frequência ou Prognóstico
}

\author{
Mariana Batista', Maria Relvas', Rebeca Calado 1, Maria Manuel Brites², Margarida Gonçalo \\ 'Médica Interna de Dermatovenereologia, Serviço de Dermatologia, Centro Hospitalar e Universitário de Coimbra, Coimbra, Portugal \\ ${ }^{2}$ Assistente Hospitalar, Serviço de Dermatologia, Centro Hospitalar e Universitário de Coimbra, Coimbra, Portugal \\ ${ }^{3}$ Assistente Hospitalar Sénior de Dermatovenereologia, Serviço de Dermatologia, Centro Hospitalar e Universitário de Coimbra, Profes- \\ sora Auxiliar Convidada da Faculdade de Medicina da Universidade de Coimbra, Coimbra, Portugal
}

RESUMO - Introdução: A dermo-hipodermite aguda bacteriana (DHAB) é uma infeção aguda da derme e hipoderme que mais frequentemente atinge os membros inferiores. Apesar de a diabetes mellitus (DM) ser frequentemente apontada como um fator de risco para o seu desenvolvimento, estudos recentes têm questionado tal relação. $O$ objetivo do presente estudo foi comparar as características da DHAB em doentes com e sem diabetes mellitus. Material e Métodos: Estudo prospetivo dos doentes hospitalizados no Serviço de Dermatologia do Centro Hospitalar e Universitário de Coimbra com o diagnóstico de DHAB entre Janeiro e Junho de 2018. Foram avaliados os seguintes parâmetros: 1) dados demográficos / biométricos género, idade; índice de massa corporal (IMC); 2) aspetos clínico-evolutivos - localização, tempo de evolução dos sintomas até ao diagnóstico, história de episódio prévio de DHBA; diagnóstico prévio de DM; 3) alterações laboratoriais - leucocitose, proteína-C reativa (PCR), pesquisa de microrganismo (sangue, pus de abcesso, exsudato de ferida, conteúdo de bolha); 3 ) terapêutica - duração da antibioterapia, necessidade de terapêutica de segunda linha, duração do internamento; 4 ) complicações locais (abcesso, necrose) ou sistémicas (bacteriémia, exantema medicamentoso, descompensação de doença subjacente e morte). Os dados foram analisados com o software SPSS, procurando sobretudo a influência da DM nos distintos parâmetros avaliados. A significância estatística foi definida para $p<0,05$. Resultados: Foram incluídos 102 doentes, 55 do género feminino $(53,9 \%)$ e 47 do masculino $(46,1 \%)$, com idade média de $68,6 \pm 13,9$ anos. O membro inferior foi o local mais atingido (73,5\%), seguido do membro superior $(20,6 \%)$ e face $(5,9 \%)$, tendo a DHBA uma média de $3,1 \pm 2,5$ dias de evolução dos sintomas à data da hospitalização. Vinte e quatro doentes tinham o diagnóstico de DM (23,5\%), seis dos quais insulinotratados (25\%). Não foi encontrada diferença estatisticamente significativa entre o grupo de diabéticos e não diabéticos para o género, idade, localização da infeção, tempo de evolução dos sintomas até à hospitalização, nem no valor dos leucócitos circulantes ou da PCR. A pesquisa de microrganismo (sangue, pus de abcesso, exsudato de ferida, conteúdo de bolha) foi positiva em $2 / 8$ diabéticos (25\%) e em $15 / 39$ não diabéticos $(38,5 \%)(p=0,138)$, tendo sido o mesmo o tipo de microrganismo isolado. A antibioterapia inicial - cefoxitina em associação a clindamicina em $64,7 \%$ - foi substituída num doente não diabético e em 10 doentes diabéticos $(p=0,451)$ e a duração total do tratamento antibiótico e do internamento entre os grupos foi semelhante. Complicações locais ocorreram em 3 diabéticos (12,5\%) e em 15 não diabéticos (19,2\%), e complicações sistémicas em 4 diabéticos $(16,7 \%)$ e em 12 não diabéticos $(15,4 \%), p=0,553$ e $p=1,000$, respetivamente. Conclusão: $O$ presente estudo demonstra que a DM em doentes hospitalizados com diagnóstico de DHAB não se associa a prior prognóstico nomeadamente necessidade de antibioterapia de segunda linha, internamento mais prolongados ou complicações locais ou sistémicas.

PALAVRAS-CHAVE - Doenças Bacterianas da Pele/diagnóstico; Doenças Bacterianas da Pele/tratamento; Celulite; Complicações da Diabetes; Erisipela; Diabetes Mellitus/complicações; Hospitalização.

Correspondência: Mariana Sousa Batista Serviço de Dermatologia

Hospitais da Universidade de Coimbra

Centro Hospitalar e Universitário de Coimbra

Av. Bissaya Barreto, Praceta Prof. Mota Pinto

3000-075 Coimbra, Portugal

E-mail: sousabatistamariana@gmail.com

DOI: https://dx.doi.org/10.29021/spdv.78.1.1148
Recelbido/Received 2019/012/14

(๑) Autor (es) (ou seu (s) empregador (es)) e Revista SPDV 2020. Reutilização permitida de acordo com CC BY-NC. Nenhuma reutilização comercial.

(c) Author(s) (or their employer(s)) and SPDV Journal 2020. Re-use permitted under CC BY-NC. No commercial re-use. 


\section{A Review of Acute Bacterial Dermo-hypodermatitis: Diabetes Mellitus Does Not Influence its Frequency or Prognosis}

ABSTRACT - Introduction: Acute bacterial dermo-hypodermatitis (DHAB) is an acute infection of the dermis and hypodermis that most often affects the lower limbs. Although diabetes mellitus has been identified as a risk factor for its development, recent studies have questioned this relationship. The aim of the present study was to compare clinical characteristics of inpatients with DHAB associated or not with diabetes mellitus. Material \& Methods: Prospective study of patients hospitalized at the Dermatology Department of the Coimbra Hospital and University Center with the diagnosis of DHAB between January and June 2018. The following parameters were evaluated: 1) demographic / biometric data-gender, age; body mass index; 2) clinical and evolutionary aspects - location of infection, interval between initial symptoms and diagnosis, history of a previous episode; previous diagnosis of diabetes mellitus; 3) laboratory abnormalities - leukocytosis, C-reactive protein (CRP), microorganism screening (blood, abscess pus, wound exudate, blister content); 3) therapy - duration of antibiotic therapy, need for second line therapy, length of hospitalization; 4) local (abscess, necrosis) or systemic complications (bacteremia, drug rash, deterioration of underlying disease and death). Data were analyzed with the SPSS software, mainly looking for the influence of diabetes mellitus on the different parameters evaluated. Statistical significance was set at $p<0.05$. Results: We included 102 patients, 55 female (53.9\%) and 47 male $(46.1 \%)$, with a mean age of $68.6 \pm 13.9$ years. The lower limb was the most affected site $(73.5 \%)$, followed by the upper limb $(20.6 \%)$ and face (5.9\%). In average there were $3.1 \pm 2.5$ days between initial symptoms and hospitalization. Twenty-four patients had a diagnosis of diabetes mellitus (23.5\%), six under insulin treatment $(25 \%)$. No statistically significant difference was found between the diabetic and non-diabetic group for gender, age, infection location, time from initial symptoms to hospitalization, neither in circulating leukocyte or CRP values. Microorganism screening (blood, abscess pus, wound exudate, blister content) was positive in $2 / 8$ diabetics $(25 \%)$ and $15 / 39$ non-diabetics $(38.5 \%)(p=0.138)$, with the same type of microorganism isolated in both groups. Initial antibiotic therapy - cefoxitin plus clindamycin in $64.7 \%$ - was replaced in one non-diabetic and 10 diabetic patients $(p=0.451)$ and the total duration of antibiotic treatment and hospitalization between groups was similar. Local complications occurred in 3 diabetics (12.5\%) and 15 non-diabetics (19.2\%), and systemic complications in 4 diabetics (16.7\%) and 12 non-diabetics (15.4\%), $p=0.553$ and $p=1.000$, respectively. Conclusion: The present study shows that diabetes mellitus in hospitalized patients diagnosed with DHAB is not associated with a worse prognosis, namely in which concerns need for second line antibiotic therapy, longer hospitalization or local/systemic complications.

KEYWORDS - Cellulitis; Diabetes Complications; Diabetes Mellitus/complications; Erysipelas; Hospitalization; Skin Diseases, Bacterial/diagnosis; Skin Diseases, Bacterial/therapy.

\section{INTRODUÇÃO}

A dermo-hipodermite aguda bacteriana (DHAB), vulgarmente também designada erisipela e/ou celulite, é uma infeção aguda da derme e hipoderme que mais frequentemente atinge os membros inferiores embora possa ocorrer em qualquer localização cutânea. Apesar de se considerar que na erisipela estão envolvidas as camadas mais superficiais e na celulite camadas mais profundas da pele ${ }^{1,2} \circ$ termo DHAB é muitas vezes utilizado de forma arbitrária para designação de ambas. Com efeito, na prática clínica é por vezes difícil estabelecer um limite claro entre estas duas entidades uma vez que é extensa a sobreposição nos aspetos clínicos, agentes causais, fatores de risco e localização. ${ }^{3}$ Por outro lado, atendendo a que a sua subcategorização não implica diferentes abordagens terapêuticas, à semeIhança de outros autores, ${ }^{4,5}$ neste estudo erisipela e celulite foram consideradas espetros clínicos da mesma entidade e o termo DHBA será usado na continuação do trabalho.

A DHAB é mais comum no género masculino, surge em média pelos 50 anos $^{6-7}$ e tem uma incidência estimada de 19-24 por 10000 habitantes nos países Europeus. ${ }^{8,9} \mathrm{O}$ número de hospitalizações por habitante/ano tende a aumentar com a idade, sendo 5 vezes superior acima dos 85 anos (incidência $>100$ por 100 000) quando comparado com as faixas etárias abaixo dos 54 anos. ${ }^{8}$ As DHBA representam assim um significativo impacto económico nos serviços de saúde. 10,11

Em adultos imunocompetentes o principal agente etiológico da DHAB é o Streptococcus pyogenes, sendo o Staphylococcus aureus menos frequentemente implicado. ${ }^{3,12} \mathrm{Em}$ menor percentagem, outros estreptococos B-hemolíticos, nomeadamente dos grupos $B, C$ e $G$, podem estar na sua origem. ${ }^{7,13}$ Não obstante, como a concentração de bactérias é baixa na lesão, ${ }^{14}$ as culturas obtidas por aspiração por agulha ou biópsia da lesão ou as hemoculturas são frequentemente negativas, ${ }^{14}$ pelo que se torna difícil conhecer a real importância relativa destes agentes microbianos. A resposta imunitária inata e adquirida ao microorganismo e às suas toxinas limitam a infeção e são responsáveis pelos sintomas clínicos.

$\mathrm{O}$ pH cutâneo ácido, a temperatura ambiente baixa e a presença de microorganismos cutâneos comensais bem 
como os péptidos antimicrobianos naturais ou induzidos são fatores que diminuem a colonização do tegumento por microrganismos patogénicos. ${ }^{15}$ Para ter acesso à derme e hipoderme o agente causal da DHAB utiliza efrações da pele (intertrigo interdigital, tinea pedis, úlceras de pressão, úlceras venosas, traumatismo local, mordedura/picada, injeção de fármaco e /ou droga, dermatose escoriada, entre outras). ${ }^{16}$ Obesidade, insuficiência venosa e linfedema também constituem fatores de risco para ocorrência de DHAB. ${ }^{17,18}$

O diagnóstico de DHBA é clínico e baseia-se na presença de sinais inflamatórios cutâneos quase sempre unilaterais, de início agudo, e com graus variáveis de extensão em profundidade. ${ }^{717}$ Caracteriza-se pelo aparecimento de uma placa eritemato-edematosa, quente e dolorosa, ${ }^{15}$ frequentemente associada a febre $(22,5 \%$ a $77,3 \%$ dos doentes hospitalizados), ${ }^{19,20}$ calafrios, náuseas e mal-estar geral. ${ }^{16,21}$ Características clínicas adicionais podem incluir bolhas, linfangite, adenopatia regional dolorosa, abcessos, necrose e hemorragia. A presença de linfangite extensa e de placa inflamatória de limites bem demarcados são características que sugerem um processo mais superficial.

As características histológicas da DHAB são inespecíficas e incluem edema dermo-hipodérmico dependendo da sua extensão em profundidade, dilatação linfática e infiltrado neutrofílico de predomínio perivascular. A presença de linfócitos e histiócitos, juntamente com tecido de granulação, é frequente em infeções com mais tempo de evolução. ${ }^{15}$

O tratamento consiste em antibioterapia sistémica empírica. Como primeira linha preconiza-se um betalactâmico, nomeadamente uma cefalosporina de primeira geração a que se pode associar a clindamicina. Em casos de ineficácia terapêutica ou DHAB grave e em localizações particulares/ ou em doentes imunodeprimidos recomenda-se um agente de espetro mais alargado como piperacilina/tazobactam ou meropenem. ${ }^{22} \mathrm{Na}$ existência de antecedentes de alergia a betalactamicos ou caso surja reação adversa no decorrer do tratamento é frequente a escolha de um fluorquinolona (levofloxacina) como segunda linha. A duração do tratamento deve ser baseada na resposta clínica, variando entre 7 a 10 dias para DHAB não complicadas. ${ }^{3}$ Em caso de episódios recorrentes (pelo menos 3 por ano), profilaxia com penicilina $G$ benzatina intramuscular mensal deve ser considerada.

No Serviço de Dermatologia do Centro Hospitalar e Universitário de Coimbra, a DHBA representa cerca de 30\% do total de internamentos (Coutinho I. Erysipelas, Cellulitis and Necrotizing Fasciitis. Oral Communication. 27 $7^{\text {th }}$ European Academy of Dermatology and Venereology Congress. Paris. 2018). Ainda que haja alguma variabilidade na decisão de hospitalização (proximidade do hospital, capacidade de realizar repouso no domicílio e acompanhamento por familiares) as principais condições que levam ao internamento prendem-se com a extensão da infeção, existência de comorbilidades e/ou constrangimentos de ordem social para cumprimento da terapêutica em ambulatório. A coexistência de diabetes mellitus (DM) como fator de risco para $\mathrm{DHAB}$ e marcador de pior prognóstico,, 23 tem sido questionada. ${ }^{15,24-25} \mathrm{O}$ presente estudo tem por objetivo caracterizar as DHBA que necessitam de hospitalização e avaliar o impacto da DM nos diversos parâmetros clinico-evolutivos.

\section{MATERIAL E MÉTODOS}

Estudo observacional prospetivo, realizado entre Janeiro e Junho de 2018, no Serviço de Dermatologia do Centro Hospitalar e Universitário de Coimbra. Foram incluídos todos os doentes hospitalizados com o diagnóstico de DHAB, excluindo-se os casos de fasceíte necrotizante. Foram estudadas as seguintes variáveis: 1) Demográficas - género, idade; 2) Clínico-evolutivos - localização, tempo de evolução antes da hospitalização, número de episódios prévios; 3) Alterações laboratoriais - leucocitose/neutrofilia, proteína-C reativa (PCR); - pesquisa de microrganismo (hemocultura/pus de abcesso/bolha); 4) Terapêutica - duração da antibioterapia, necessidade de mudança para terapêutica de segunda linha, duração do internamento; 5) Complicações locais abcesso, necrose; 6) Complicações sistémicas - bacteriémia, toxidermia, descompensação de doença subjacente e morte.

Foram caracterizados e comparados 2 grupos distintos de doentes (diabéticos versus não diabéticos). A análise estatística foi obtida com recurso ao software SPSS tendo sido considerada uma significância estatística de $p<0,05$.

\section{RESULTADOS}

O estudo inclui 102 doentes, 55 do género feminino $(53,9 \%)$ e 47 do género masculino $(46,1 \%)$, com uma média de idades de 68,6 1 13,9 anos. $O$ índice de massa corporal (IMC) avaliado em 67 doentes foi de 29,7 $\pm 6,0 \mathrm{~kg} /$ $\mathrm{m}^{2}$. A maioria das infeções localizou-se no membro inferior (73,5\%), seguido do membro superior $(20,6 \%)$ e face $(5,9 \%)$. A sintomatologia iniciou-se, em média, 3,1 $1 \pm 2,5$ dias antes da admissão hospitalar. Trinta e um doentes já se encontravam sob antibioterapia à data da admissão hospitalar $(30,4 \%)$ e a mesma percentagem (31/102) tinha história de episódio prévio de DHAB.

Uma placa inflamatória foi observada em todos os doentes $(n=102)$, associada a linfangite em $62(60,8 \%)$ e adenopatia satélite em $45(44,1 \%)$, frequentemente associadas a uma placa eritematosa e infiltrada, sobretudo na face ântero-interna da coxa nos casos localizados no membro inferior (Fig. 1). A maioria dos doentes teve febre (temperatura axilar $\left.>38^{\circ} \mathrm{C}\right)$ durante o internamento $(60,8 \%)$, com valor máximo médio de $38,6 \pm 0,4^{\circ} \mathrm{C}$.

Relativamente aos parâmetros inflamatórios, observou-se leucocitose e neutrofilia, respetivamente em 83/102 $(81,4 \%)$ e $53 / 58(91,4 \%)$ dos doentes em que os parâmetros foram avaliados, com valores médios de leucócitos 14100 $\pm 5800 / \mathrm{uL}$, e percentual de neutrófilos $82,1 \pm 9,6 \%$. A PCR estava elevada em 99 doentes $(97,1 \%)$ com uma média de $18,9 \pm 11,6 \mathrm{mg} / \mathrm{dL}$ para o valor máximo registado durante o internamento. A pesquisa do agente causal, por hemocultura, ou cultura do pus de abcesso, exsudato de ferida, ou conteúdo de bolha realizada em 47 indivíduos revelou 


\section{Artigo Original}

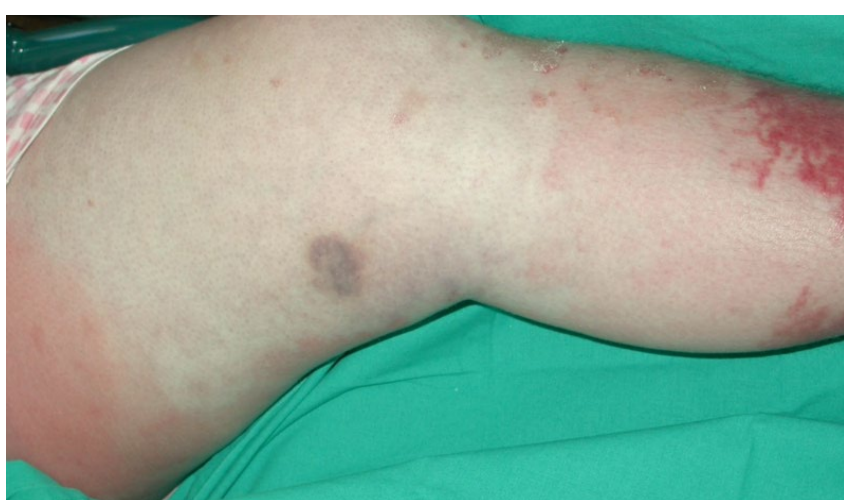

Figura 1 - Linfangite: placa eritematosa e infiltrada localizada à face ântero-interna da coxa num doente com DHAB do membro inferior esquerdo.

microorganismos em $17(36,2 \%)$ doentes: Staphylococcus aureus sensível à meticilina $(n=6)$, Staphylococcus aureus resistente à meticilina $(n=4)$, Streptococos pyogenes $(n=4)$, Streptococos intermedius $(n=1)$, Streptococos equisimilis $(n=1)$, Pseudomonas aeruginosa $(n=1)$.

Os doentes cumpriram, em média, 14,5 $\pm 3,6$ dias de antibioterapia e apenas $10,8 \%$ necessitaram de antibioterapia de segunda linha.

A duração média do internamento foi de $12,9 \pm 7,8$ dias. Ocorreram complicações locais em 18 doentes $(17,6 \%)$ - abcesso ( $n=11)$, necrose ( $n=4)$ (Fig. 2), e complicações sistémicas em $16(15,7 \%)$ - bacteriémia $(n=2)$, exantema medicamentoso $(n=11)$, descompensação de doença subjacente $(n=2)$ e morte $(n=1)$ (Tabela 1).

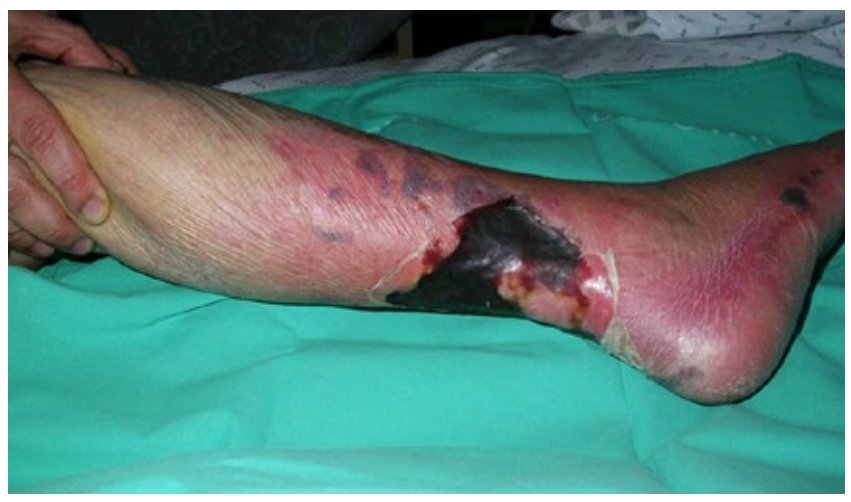

Figura 2 - DHAB da perna esquerda complicada de placa de necrose.

Dos 102 doentes, 24 tinham o diagnóstico de DM $(23,5 \%), 18$ não insulinotratados (75\%) e 6 insulinotratados (25\%). Destes, 14 eram do género feminino e 10 do género masculino, com idade média $73,3 \pm 12,3$ anos. O IMC no grupo de diabéticos foi de $33,4 \pm 6,1 \mathrm{~kg} / \mathrm{m}^{2}$.

Não se observou diferença estatisticamente significativa entre o grupo de diabéticos e não diabéticos para
Tabela 1 - População do estudo: características gerais.

\begin{tabular}{|c|c|}
\hline & Total $(n=102)$ \\
\hline $\begin{array}{l}\text { Género } \\
\text { Feminino } \\
\text { Masculino }\end{array}$ & \begin{tabular}{l|l}
55 & $53,9 \%$ \\
47 & $46,1 \%$
\end{tabular} \\
\hline $\begin{array}{l}\text { Idade (anos) } \\
\text { Min-Máx } \\
\text { Média + SD }\end{array}$ & $\begin{array}{c}38-98 \\
68,6 \pm 13,9\end{array}$ \\
\hline $\begin{array}{l}\text { IMC }\left(\mathrm{kg} / \mathrm{m}^{2}\right) \\
\text { Min- Máx } \\
\text { Média } \\
\text { IMC } 25-30 \\
\text { IMC > 30 }\end{array}$ & $\begin{array}{c}n=67 \\
19,8-45,1 \\
29,7 \pm 6,0 \\
n=21 \mid 20,6 \% \\
n=29 \mid 28,4 \%\end{array}$ \\
\hline $\begin{array}{l}\text { Localização } \\
\text { Membro inferior } \\
\text { Membro superior } \\
\text { Face }\end{array}$ & \begin{tabular}{l|l}
75 & $73,5 \%$ \\
21 & $20,6 \%$ \\
6 & $5,9 \%$
\end{tabular} \\
\hline Dias até internamento & $3,1 \pm 2,5$ dias \\
\hline $\begin{array}{l}\text { Antibioterapia prévia ao } \\
\text { internamento }\end{array}$ & $31 \mid 30,4 \%$ \\
\hline $\begin{array}{l}\text { Episódio prévio de DHBA } \\
\text { Doentes com }>1 \text { episódio }\end{array}$ & \begin{tabular}{l|l}
$31 \mid 30,4 \%$ \\
$15 \mid 14,7 \%$
\end{tabular} \\
\hline $\begin{array}{l}\text { Nºpisódios prévios } \\
\text { Min-Máx } \\
\text { Média }\end{array}$ & $\begin{array}{c}1-22 \\
3,7 \pm 5,4\end{array}$ \\
\hline $\begin{array}{l}\text { Achados clínicos } \\
\text { Febre } \\
\text { Placa inflamatória } \\
\text { Lingangite } \\
\text { Adenopatia satélite }\end{array}$ & $\begin{array}{l}62 \mid 60,8 \% \\
102 \mid 100 \% \\
62 \mid 60,8 \% \\
45 \mid 44,1 \%\end{array}$ \\
\hline $\begin{array}{l}\text { Parâmetros laboratoriais* } \\
\text { Leucócitos (n/uL) } \\
\text { Min-Máx } \\
\text { Média } \pm \text { SD } \\
\text { Neutrófilos (\%) } \\
\text { Min-Máx } \\
\text { Média } \pm \text { SD } \\
\text { PCR (mg/dL) } \\
\text { Min-Máx } \\
\text { Média } \pm \text { SD }\end{array}$ & $\begin{array}{c}\text { Valores e média } \\
\begin{array}{c}3,2-33,4 \\
14,1 \pm 5,8 \\
46-93,6 \\
82,1 \pm 9,6 \\
0,7-53,7 \\
18,9 \pm 11,6\end{array}\end{array}$ \\
\hline $\begin{array}{l}\text { Tratamento } \\
\text { Necessidade ATB } 2^{a} \text { linha } \\
\text { Duração ATB (dias) } \\
\text { Duração internamento (dias) }\end{array}$ & $\begin{array}{l}11 \mid 10,8 \% \\
14,5 \pm 3,6 \\
12,9 \pm 7,8\end{array}$ \\
\hline $\begin{array}{l}\text { Complicações } \\
\text { Locais } \\
\text { Sistémicas }\end{array}$ & \begin{tabular}{r|r|}
18 & $17,6 \%$ \\
$\mathbf{1 6} \mid 15,7 \%$
\end{tabular} \\
\hline
\end{tabular}

IMC - índice de massa corporal; DHAB-dermohipodermite aguda bacteriana; PCR-proteína C-reactiva sérica; ATB - antibioterapia 


\section{Artigo Original}

Tabela 2 - Comparação do perfil epidemiológico e clínico do grupo de diabéticos versus não diabéticos.

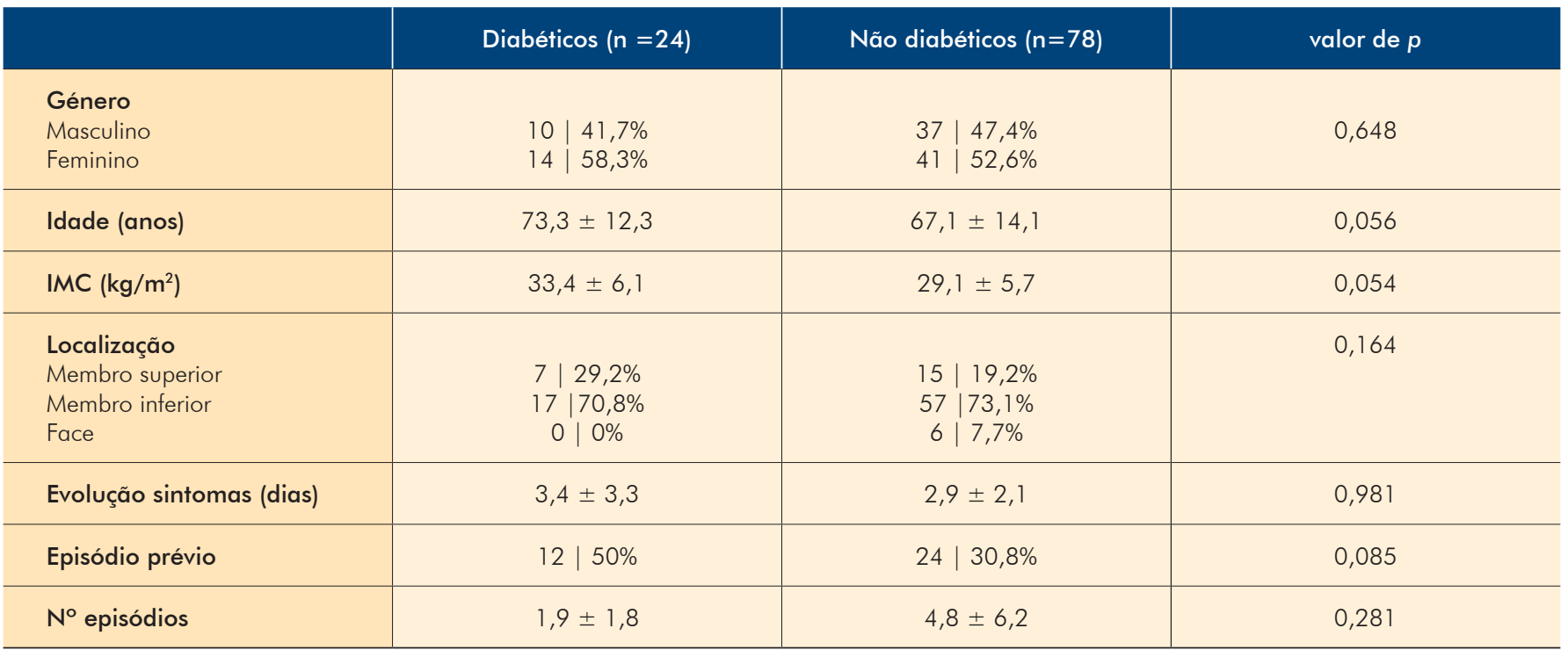

características demográficas (género, idade), IMC, localização da infeção, tempo de evolução dos sintomas, ocorrência e número de episódios prévios de DHAB (Tabela 2).

Quanto às alterações laboratoriais não foi igualmente observada diferença no valor dos leucócitos e da PCR entre os dois grupos. A pesquisa de microrganismo foi positiva em 2/8 diabéticos (25\%) e em 15/39 não diabéticos (38,5\%), não se observando diferença entre os grupos, tanto na positividade da pesquisa, como no tipo de microrganismo isolado (Tabela 3).

Formação de abcesso ou necrose ocorreu em $8,3 \%$ e 4,2\% dos doentes diabéticos e em $14,1 \%$ e $5,1 \%$ nos doentes não diabéticos, respetivamente. Relativamente às complicações sistémicas como bacteriémia, toxidermia, descompensação de doença crónica e morte também não se observou diferença estatisticamente significativa entre os dois grupos (Tabela 4). A duração média do internamento foi de 13,9 $\pm 7,4$

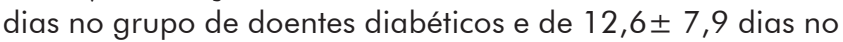
grupo de não diabéticos $(p=0,136)$ (Tabela 4).

\section{DISCUSSÃO}

O presente estudo com um número reduzido de DHAB tem características sobreponíveis a outros estudos mas distancia-se noutros aspetos. Apesar de descrita como mais prevalente no género masculino, ${ }^{6,26}$ no presente estudo o género feminino representou a maioria dos casos $(53,9 \%$ vs $46,1 \%)$, à semelhança do reportado por Wojas-Pelc et al. ${ }^{27}$

A DHAB surge mais frequente nas faixas etárias mais

Tabela 3 - Comparação dos resultados dos exames laboratoriais e antibioterapia entre o grupo de diabéticos versus não diabéticos.

\begin{tabular}{|c|c|c|c|}
\hline & Diabéticos $(n=24)$ & Não diabéticos $(n=78)$ & Valor de $p$ \\
\hline $\begin{array}{l}\text { Leucocitose } \\
\text { Valor absoluto dos Leucócitos (/uL) }\end{array}$ & $\begin{array}{c}n= \\
14 ., \pm 6,9\end{array}$ & $14,0 \pm 5,4$ & 0,734 \\
\hline $\begin{array}{l}\text { Elevação da PCR (n doentes e \%) } \\
\text { PCR máxima }(\mathrm{mg} / \mathrm{dL})\end{array}$ & $19,5 \pm 8,6$ & $18,8 \pm 12,5$ & 0,418 \\
\hline Tempo antibioterapia (dias) & $14,3 \pm 2,8$ & $14,6 \pm 3,8$ & 0,765 \\
\hline
\end{tabular}




\section{Artigo Original}

Tabela 4 - Comparação das complicações e duração do internamento entre o grupo de diabéticos versus não diabéticos.

\begin{tabular}{|c|c|c|c|}
\hline & Diabéticos $(n=24)$ & Não diabéticos $(n=78)$ & Valor de $p$ \\
\hline $\begin{array}{l}\text { Complicações locais } \\
\text { Abcesso } \\
\text { Necrose }\end{array}$ & $\begin{array}{c}3(12,5 \%) \\
n=2 \\
n=1\end{array}$ & $\begin{array}{c}15(19,2 \%) \\
n=11 \\
n=4\end{array}$ & 0,553 \\
\hline $\begin{array}{l}\text { Complicações sistémicas } \\
\text { Bacteriémia } \\
\text { Exantema maculopapuloso } \\
\text { Descompensação doença crónica } \\
\text { Morte }\end{array}$ & $\begin{array}{c}4(16,7 \%) \\
- \\
n=3 \\
n=1 \\
-\end{array}$ & $\begin{array}{c}12(15,4 \%) \\
n=2 \\
n=8 \\
n=1 \\
n=1\end{array}$ & 1,000 \\
\hline Duração internamento (dias) & $13,9 \pm 7,4$ & $12,6 \pm 7,9$ & 0,136 \\
\hline
\end{tabular}

altas. A idade média da população estudada (68,6 anos) foi superior ao reportado por Mokni $(45,6 \text { anos })^{23}$ e Krasgakis et al (54,5 anos), ${ }^{28}$ mas não muito distinta de outros estudos. ${ }^{27,29} \mathrm{~A}$ faixa etária mais alta poderá explicar o maior número de comorbilidades no presente estudo, ainda que a presença destas comorbilidades tenha sido certamente um fator de peso para a opção por antibioterapia parentérica e hospitalização e, consequentemente, inclusão no estudo.

O valor médio do IMC do grupo estudado foi $29,7 \mathrm{~kg} /$ $\mathrm{m}^{2}(\mathrm{n}=67)$, portanto próximo do que se considera excesso de peso, e 29 doentes $(43,3 \%)$ tinham IMC> 30 , dos quais 15 referia um episódio prévio de DHBA. A percentagem de casos com DHBA prévia foi superior nestes doentes com IMC $>30(48,4 \%)$ comparativamente aos com IMC $<30 \quad(16 \%$ $-42,1 \%)$, mas sem atingir um valor estatisticamente significativo $(p=0,058)$. Estes dados corroboram a importância da obesidade como fator de risco para DHAB primária e recorrente, ${ }^{3,15}$ e a necessidade de fomentar medidas para $\circ$ controlo do excesso ponderal. . $^{76,29}$

O local mais comumente atingido foi o membro inferior $(73,5 \%)$ tal como na maioria dos estudos, ${ }^{6,30}$ ainda que numa percentagem inferior aos $90 \%$ de Bonnetblanc et al. ${ }^{21}$ O envolvimento do membro superior $(20,6 \%)$ e da face $(5,9 \%)$ foi superior ao de outros estudos, respetivamente $5 \%$ e $2,5 \%{ }^{21}$

A febre $(60,8 \%)$ e os parâmetros laboratoriais inflamatórios são típicos de $\mathrm{DHAB}, 7$ mas salientamos valores médios de leucocitose e PCR acima do descrito por Kozlowska et $a l,{ }^{29}$ eventualmente relacionado com o facto de ter sido registado o valor máximo destes parâmetros durante o internamento.

A duração do tratamento antibiótico recomendada na DHBA varia entre 10 e 20 dias, devendo ser ajustada a cada caso em função da sua evolução. ${ }^{13}$ Se considerarmos a média to tempo total de antibioterapia neste estudo $(14,5$ $\pm 3,6$ dias), que inclui a terapêutica realizada após a alta hospitalar, este foi superior ao de outras séries, mas estas incluem doentes de ambulatório habitualmente menos graves e sem complicações. ${ }^{7}$ Se considerarmos apenas a antibioterapia durante $\mathrm{o}$ internamento até à data da alta $(12,9 \pm$
7,8 dias) o tempo foi semelhante à descrita por Kozlowska et al. ${ }^{29} \mathrm{O}$ longo tempo de tratamento no presente estudo prende-se com o facto de incluirmos apenas doentes que necessitaram de hospitalização e com a manutenção do antibiótico nas fases mais tardias da DHBA em que ainda são evidentes sinais inflamatórios (eritema, infiltração, edema linfático) mas já sem sinais biológicos de infeção e que muito provavelmente não têm já relação com a presença ou proliferação do microorganismo na pele.

A maioria dos doentes, tal como noutros centros, ${ }^{29}$ cumpriu dupla antibioterapia. A associação de cefoxitina e clindamicina foi a mais habitual tendo apenas $10,8 \%$ dos doentes necessitado de antibioterapia de segunda linha. No entanto, estudos têm demonstrado que antibioterapia dupla instituída precocemente em DHAB não complicadas não se associa a melhores resultados quando comparado com monoterapia. ${ }^{31,32}$ Complicações sistémicas como bacteriemia, descompensação de doença subjacente ou morte descritas em $<5 \%$ dos $\operatorname{casos}^{23}$ foram observadas em apenas 5 doentes $(4,9 \%)$. Complicações locais como abcesso ou necrose ocorreram em 15 doentes $(14,7 \%)$, percentagens semelhantes às reportadas na literatura. ${ }^{27,29}$

No presente estudo $23,5 \%$ dos doentes tinham o diagnóstico de $D M$, percentagem que vai de encontro à prevalência estimada de DM em Portugal na faixa etária dos 60-79 anos $(27 \%$ da população, com $16,7 \%$ de casos diagnosticados, $10,3 \%$ não diagnosticada). ${ }^{33}$ Assim, considera-se que a população do estudo é representativa e sugere-se que, não estando sobrerrepresentada no presente estudo $(23,5 \%$ vs $27 \%$ na população geral), a DM não parece ser fator de risco significativo para DHAB que motive hospitalização.

A coexistência de DM não se associou a diferenças significativas de género, idade e IMC, localização da DHAB, presença de alterações laboratoriais e seu valor máximo, nomeadamente no que diz respeito à leucocitose, neutrofilia e elevação da PCR e maior frequência de isolamentos bacteriológicos do sangue ou pele. A percentagem de doentes diabéticos com episódios prévios foi superior ( $50 \%$ vs $30,8 \%$ ) mas o número destes episódios foi muito inferior $(1,9$ vs 4,8$)$ (Tabela 2). 
Contrariamente a um estudo conduzido por Kozłowska et al $^{29}$ a DM não se associou a internamento mais prolongado, cursos de antibioterapia mais longos, maior necessidade de antibioterapia de segunda linha ou maior número de complicações locais e/ou sistémicas, sugerindo que a DM não agrava o prognóstico destes doentes.

A inexistência de critérios pré-estabelecidos para internamento, o facto de se tratar de uma amostra de pequena dimensão e a colheita de alguns dados de forma não sistemática (exame bacteriológico, IMC) constituem as principais limitações do estudo.

\section{CONCLUSÃO}

Apesar de a DM ter vindo a ser apontada como fator de risco para a ocorrência de $\mathrm{DHAB}$, facto que não confirmámos no presente estudo pelo menos para as formas de DHBA que justifiquem hospitalização, esta comorbilidade também não parece estar associada a marcadores de maior gravidade ou modificar o prognóstico dos doentes hospitalizados com DHAB.

Conflitos de interesse: Os autores declaram a inexistência de conflitos de interesse na realização do presente trabalho.

Fontes de financiamento: Não existiram fontes externas de financiamento para a realização deste artigo.

Confidencialidade dos dados: Os autores declaram ter seguido os protocolos da sua instituição acerca da publicação dos dados de doentes.

Protecção de pessoas e animais: Os autores declaram que os procedimentos seguidos estavam de acordo com os regulamentos estabelecidos pelos responsáveis da Comissão de lnvestigação Clínica e Ética e de acordo com a Declaração de Helsínquia da Associação Médica Mundial.

Proveniência e revisão por pares: Não comissionado; revisão externa por pares.

Conflicts of interest: The authors have no conflicts of interest to declare.

Financing support: This work has not received any contribution, grant or scholarship.

Confidentiality of data: The authors declare that they have followed the protocols of their work center on the publication of data from patients.

Protection of human and animal subjects: The authors declare that the procedures followed were in accordance with the regulations of the relevant clinical research ethics committee and with those of the Code of Ethics of the World Medical Association (Declaration of Helsinki).

Provenance and peer review: Not commissioned; externally peer reviewed

\section{ORCID}

Mariana Batista

https://orcid.org/000-0003-3442-615x

Margarida Gonçalo

http://orcid.org/0000-0001-6842-1360

\section{REFERÊNCIAS}

1. Bisno AL, Stevens DL. Streptococcal infections of skin and soft tissues. N Engl J Med. 1996;334:240-5. doi:10.1056/NEJM199601253340407

2. Swartz MN. Clinical practice. Cellulitis. N Engl J Med. 2004;350:904-12. doi:10.1056/NEJMcp031807

3. Stevens DL, Bisno AL, Chambers HF, et al. Practice guidelines for the diagnosis and management of skin and soft tissue infections: 2014 update by the Infectious Diseases Society of America. Clin Infect Dis. 2014;59:e 1052. doi:10.1093/cid/ciu444

4. Kilburn SA, Featherstone P, Higgins B, Brindle R. Interventions for cellulitis and erysipelas. Cochrane database Syst Rev. 2010;CD004299. doi:10.1002/14651858. CD004299.pub2

5. Grosshans E. Érysipèle. Classification anatomoclinique, terminologie. Ann Dermatol Venereol. 2001;128:307311. PMID: 11319356

6. Inghammar $M$, Rasmussen $M$, Linder A. Recurrent erysipelas--risk factors and clinical presentation. BMC Infect Dis. 2014;14:270. doi:10.1186/1471-2334-14-270

7. Christensen KLY, Holman RC, Steiner CA, Sejvar JJ, Stoll BJ, Schonberger LB. Infectious disease hospitalizations in the United States. Clin Infect Dis. 2009;49:10251035. doi: $10.1086 / 605562$

8. Blackberg A, Trell K, Rasmussen M. Erysipelas, a large retrospective study of aetiology and clinical presentation. BMC Infect Dis. 2015;15:402. doi:10.1186/ s1 2879-015-1134-2

9. Goettsch WG, Bouwes Bavinck JN, Herings RMC. Burden of illness of bacterial cellulitis and erysipelas of the leg in the Netherlands. J Eur Acad Dermatol Venereol. 2006;20:834-9. doi:10.1111/ i. 1468-3083.2006.01657.x

10. Bartholomeeusen S, Vandenbroucke J, Truyers C, Buntinx F. Epidemiology and comorbidity of erysipelas in primary care. Dermatology. 2007;215:118-22. doi: $10.1159 / 000104262$

11. Nathwani D. The Management of skin and soft tissue infections: outpatient parenteral antibiotic therapy in the United Kingdom. Chemotherapy. 2001;47:17-23. doi:10.1159/000048564

12. Ostermann H, Blasi F, Medina J, Pascual E, McBride K, Garau J, et al. Resource use in patients hospitalized with complicated skin and soft tissue infections in Europe and analysis of vulnerable groups: the REACH study. J Med Econ. 2014;17:719-29. doi:10.3111/13696998. 2014.940423

13. Bernard $P$, Bedane $C$, Mounier M, Denis F, Catanzano G, Bonnetblanc JM. Streptococcal cause of erysipelas and cellulitis in adults. A microbiologic study using a direct immunofluorescence technique. Arch Dermatol. 1989; 125:779-82.

14. Caetano M, Amorin I. Erisipelas. Acta Med Port. 18:38593. 


\section{Artigo Original}

15. Chira S, Miller LG. Staphylococcus aureus is the most common identified cause of cellulitis: a systematic review. Epidemiol Infect. 2010;138:313-7. doi:10.1017/ s0950268809990483

16. Raff AB, Kroshinsky D. Cellulitis: A Review. JAMA. 2016;316:325-37. doi:10.1001/jama.2016.8825

17. Morris AD. Cellulitis and erysipelas. BMJ Clin Evid. 2008;2008. pii: 1708.

18. Dupuy A, Benchikhi H, Roujeau J-C, Bernard P, Vaillant $\mathrm{L}$, Chosidow $\mathrm{O}$, et al. Risk factors for erysipelas of the leg (cellulitis): case-control study. BMJ. 1999;318:1591 4. doi:10.1136/bmj.318.7198.1591

19. Bjornsdottir S, Gottfredsson M, Thorisdottir AS, Gunnarsson GB, Ríkardsdóttir H, Kristiánsson M, et al. Risk Factors for Acute Cellulitis of the Lower Limb: A Prospective Case-Control Study. Clin Infect Dis. 2005;41:1416-22. doi: 10.1086/497127

20. Koutkia P, Mylonakis E, Boyce J. Cellulitis: evaluation of possible predisposing factors in hospitalized patients. Diagn Microbiol Infect Dis. 1999;34:325-7. doi:10.1016/S0732-8893(99)00028-0

21. Kulthanan K, Rongrungruang $Y$, Siriporn A, Boonchai W, Suthipinittharm P, Sivayathorn A, et al. Clinical and microbiologic findings in cellulitis in Thai patients. J Med Assoc Thai. 1999;82:587-92. PMID: 10443081

22. Bonnetblanc JM, Bedane C. Erysipelas: recognition and management. Am J Clin Dermatol. 2003;4:157-63. doi:10.2165/00128071-200304030-00002

23. Kwak YG, Choi S-H, Kim T, Park SY, Seo SH, Kim MB, et al. Clinical Guidelines for the Antibiotic Treatment for Community-Acquired Skin and Soft Tissue Infection. Infect Chemother. 2017;49:301-25. doi:10.3947/ ic. 2017.49.4.301

24. Mokni M, Dupuy A, Denguezli M, Dhaoui R, Bouassida $S$, Amri $M$, et al. Risk factors for erysipelas of the leg in Tunisia: a multicenter case-control study. Dermatology. 2006;212:108-12. doi:10.1159/000090649

25. Quirke M, Ayoub F, McCabe A, Boland F, Smith B,
O'Sullivan $R$, et al. Risk factors for nonpurulent leg ceIlulitis: a systematic review and meta-analysis. Br J Dermatol. 2017;177:382-94. doi:10.1111/bjd.15186

26. Smolle J, Kahofer P, Pfaffentaler E, Kerl H. Risikofaktoren fur das auftreten von lokalen komplikationen beim erysipel. Hautarzt. 2000;51:14-18. doi:10.1007/ s001050050004

27. Wojas-Pelc A, Alekseenko A, Jaworek AK. Erysipelas course of disease, recurrence, complications; a 10 years retrospective study. Przeglad Epidemiol. 2007;61:45764.

28. Krasagakis K, Valachis A, Maniatakis P, Kruger-Krasagakis S, Samonis G, Tosca AD. Analysis of epidemiology, clinical features and management of erysipelas. Int J Dermatol. 2010;49:1012-7.

29. Kozłowska D, Myšliwiec H, Kiluk P, Baran A, Milewska AJ, Flisiak I. Clinical and epidemiological assessment of patients hospitalized for primary and recurrent erysipelas. Przegl Epidemiol. 70:575-84.

30. Lazzarini L, Conti E, Tositti G, de Lalla F. Erysipelas and cellulitis: clinical and microbiological spectrum in an Italian tertiary care hospital. J Infect. 2005;51:383-9. doi:10.1016/i.jinf.2004.12.010

31. Pallin DJ, Binder WD, Allen MB, Lederman M, Parmar $S$, Filbin $M R$, et al. Clinical trial: comparative effectiveness of cephalexin plus trimethoprim-sulfamethoxazole versus cephalexin alone for treatment of uncomplicated cellulitis: a randomized controlled trial. Clin Infect Dis. 2013;56:1754-62. doi:10.1093/cid/cit1 22

32. Brindle R, Williams OM, Davies P, Harris T, Jarman $H$, Hay $A D$, et al. Adjunctive clindamycin for cellulitis: A clinical trial comparing flucloxacillin with or without clindamycin for the treatment of limb cellulitis. BMJ Open. 2017;7:e013260. doi: 10.1136/bmjopen-2016-013260

33. Diabetes: Factos e Números - O Ano de 2015 - Relatório Anual do Observatório Nacional da Diabetes. Lisboa: Sociedade Portuguesa de Diabetologia;2016. 